\title{
Morphological changes of the anterior alveolar bone due to retraction of anterior teeth: a retrospective study
}

\section{Qiannan Sun}

Peking University School of Stomatology

\section{Si Chen}

Peking University School of Stomatology

Wenhsuan Lu

Peking University School of Stomatology

\section{Yunfan Zhang}

Peking University School of Stomatology

\section{Liying Peng}

Peking University School of Stomatology

Bing Han ( $\sim$ kqbinghan@bjmu.edu.cn )

Peking University School of Stomatology https://orcid.org/0000-0003-4584-1092

\section{Research article}

Keywords: Alveolar bone morphology, Incisor retraction, Point A, Point B

Posted Date: October 30th, 2019

DOI: https://doi.org/10.21203/rs.2.11278/v3

License: (1) This work is licensed under a Creative Commons Attribution 4.0 International License.

Read Full License

Version of Record: A version of this preprint was published at Head \& Face Medicine on July 16th, 2021. See the published version at https://doi.org/10.1186/s13005-021-00277-z. 


\section{Abstract}

Background: The morphology of the anterior alveolar bone may change after the retraction of incisors in premolar extraction cases in orthodontics. Methods: Pre- (T0) and post-treatment (T1) lateral cephalograms of 477 subjects in the maxilla and 226 subjects in the mandible who underwent the orthodontic treatment with extraction of 2 premolars in upper or lower arches were included. Alveolar bone width and height in both the maxillary and mandible incisor area were measured at T0 and T1 respectively. By superimposing the TO and $\mathrm{T} 1$ cephalometric tracings, changes of points $A$ and $B$, and the movement of the incisors were also measured. Results: The alveolar bone width (ABW) showed a significant decrease in both maxilla and mandible $(P<0.001)$ except the labial side of the mandible, which exhibited slight increase, though statistically insignificant $(P>0.05)$. The alveolar bone height $(A B H)$ showed a significant increase in the labial side of maxilla and a significant decrease in the lingual side of maxilla and mandible. A strong positive correlation was observed between incisor movement and position changes of points $A$ and $B$ both in the horizontal and vertical direction. Conclusions:

Anterior alveolar bone width and height generally decreased after orthodontic treatment. Incisor retraction led to a significant position changes of points $A$ and $B$.

\section{Background}

Tooth extraction is a common dental procedure used to treat dentition crowding and to allow for the retraction of the anterior teeth, thus reducing facial convexity and morphologically altering the alveolar bone surrounding the anterior teeth[1]. Thus, the extent of alveolar retraction resulting from orthodontic treatment is directly related to the final treatment results[2] . Moreover, with the advancements in techniques, particularly the widespread use of implant anchorage, the indications of orthodontic treatment have expanded. Therefore, the extent of tooth movement has remarkably expanded and good outcomes are achieved in cases with various complex dentomaxillofacial deformities. However, it is unclear whether alveolar bone remodeling that occurs during orthodontic treatment always follows the direction and extent of tooth movement.

In orthodontic tooth movement, force induces alveolar bone resorption on the pressure side and bone apposition on the tension side[3]. A classical theory in orthodontics is that the alveolar bone follows the direction of tooth movement and the width of alveolar bone remains unchanged [4]. If this theory were correct, the teeth could be moved to any position in the mouth, as needed. However, many studies which assessed the periodontal status after orthodontic treatment have reported that excessive retraction of the anterior teeth may lead to iatrogenic sequelae such as alveolar bone loss, dehiscence, fenestration, and gingival recession[5-9]. Therefore, it's important to verify the true capability for bone remodeling in alveolar bone to avoid the unwanted side-effects. Previous studies evaluating the relationship between incisor retraction and alveolar bone width/height included a small sample size, which may affect the accuracy of the conclusions. 
Point $A$, where the lower front edge of the anterior nasal spine meets the front wall of the maxillary alveolar process and point $B$, the most posterior point on the anterior surface of mandibular symphysis are commonly used as indicators of the sagittal relationship between the maxilla and mandible in many analyses[10]. However, the two anatomic landmarks are affected by the anterior alveolar bone remodeling with growth and orthodontic treatment[11, 12]. A few studies have attempted to investigate the effect of incisor inclination on the position of points A and B. Erverdi [12] showed a direct correlation between incisor inclination changes and point $A$. Hassan et al. [13]found that if the upper incisor is retroclined by $10^{\circ}$, point A will move superiorly by $0.6 \mathrm{~mm}$. In another study by Bicakci et al.[14], it was found that the proclination of the maxillary incisors along with the backward movement of the incisor root apex causes a change in the horizontal position of point A. It was suggested to use the linear movement of the incisor apex, rather than the angular measurements to evaluate the sagittal change of point A [14]. Nevertheless, research on this topic has been limited thus far.

In the present study, we aimed to evaluate the changes in anterior alveolar bone width (ABW) and height $(A B H)$ after incisor retraction and investigate the relationship between tooth movement and the position changes of points $A$ and $B$.

\section{Methods}

The study sample was selected from a database comprising over 11,000 patients who had and completed orthodontic treatment between 1997 and 2005 at Peking University School and Hospital of Stomatology. All the records were anonymized and de-identified prior to analysis. This retrospective cephalometric study was approved by the Institutional Ethics Committee (NO.: PKUSSIRB-201626016).

The inclusion and exclusion criteria were as follows: (1) Han Chinese ethnicity; (2) fixed-appliance orthodontic treatment with extraction of 2 premolars in upper and/or lower arches囚respectively; (3) mean distance of the lingual movements of point UIE and LIE were more than $3 \mathrm{~mm}$ in maxilla and mandible, respectively. (4) availability of the pre- and post-treatment lateral cephalograms which were of sufficient quality for identifying the relevant landmarks, all taken by the same X-ray machine; (5) lack of any significant medical history; (6) no craniofacial congenital malformation such as cleft lip and palate and syndromic disease; and (7) no need for orthognathic surgery.

Sample-size calculation was based on the significant results from a similar study by Lund et al.[16], who studied alveolar bone changes after orthodontic treatment (the difference of means 0.2 , and the difference of the standard deviations 0.9). PASS 2019 was used for sample size calculation, with with the established significance level and power of the test set at 0.05 and $80 \%$ respectively, the sample size would be 161 .

In the maxilla, pre-treatment (T0) and post-treatment (T1) cephalograms of 477 individuals (217 class I and 260 class II/1, 337 females and 140 males) who met the selection criteria were included in this study. The patients ranged in age from 11 to 34 years, with an average age of 14.69 years. 
In the mandible, 226 subjects (121 class I and 105 class II/1, 154 females and 72 males) aged from 11 to 35 years (mean age 15.03 years) qualified for the retrospective analysis.

The treatment protocol was standardized using an MBT (McLaughlin, Bennett, Trevisi) pre-adjusted appliance (Hangzhou Shinye Orthodontic Products; Hangzhou, China) with 0.022-inch slots. Maximum anchorage mechanics were planned for all patients and all patients were experienced space closure with sliding mechanics and light forces. Cephalograms were taken before treatment (T0) and immediately after treatment (T1).

\section{Cephalometric analysis}

To control for magnification, all lateral cephalograms were taken with the same cephalostat with the consistent object-film distance. After the cephalograms were scanned, cephalometric landmarks were located three times each by three senior residents who had undergone calibration training and were blinded to the study objectives. The points with higher dispersion were automatically detected by a customized software and were checked by the same resident. The average of the nine locations of each landmark was used in subsequent calculations by the customized cephalometric software. The cephalometric landmarks and reference planes are shown and explained in Fig 1 and Table 1.

The ABW of the labial, palatal/lingual and total alveolar crest were determined at the level of the center of resistance of the central incisors, which in this study was defined as a point located on the long axis of the tooth at a distance of $1 / 3$ of the root length when measured from the alveolar crest (Fig. 2)[17]. UIR and LIR were used to represent the center of resistance of the central incisors in the maxilla and mandible respectively. A line passing through the center of resistance and parallel with the AC line (a line that connects the labial and palatal /lingual alveolar crest points) was used as the reference line (the observed level for alveolar bone width measurements). To ensure the consistency of the observed level, the distance between the $\mathrm{AC}$ line and the reference line on the pre-treatment cephalogram was recorded and then transferred to the post-treatment cephalogram. At this level, the labial (anterior), palatal/lingual (posterior), and total alveolar bone width was assessed in the maxilla (ABWL1, ABWP1, and ABWT1) and mandible (ABWL2, ABWP2, and ABWT2) at T0 and T1 respectively.

The $\mathrm{ABH}$ was measured as the vertical distance from both the labial and palatal/lingual side of the alveolar crest to the palatal plane in the maxilla (ABHL1 and ABHP1) and to the mandibular plane in the mandible (ABHL2 and ABHP2) (Fig.2).

The changes in the position of the upper incisor and point A were measured by superimposing the T0 and T1 lateral cephalograms on the palatal plane at the anterior nasal spine point (ANS) (Fig. 3a). On this superimposition, a horizontal line passing through the sella, parallel with the Frankfort plane, was drawn to form a horizontal reference line. A line perpendicular to the horizontal reference line, passing through the sella, was used as the vertical reference line. Three points on the most prominent upper central incisor- the incisal edge point (UIE), the center of resistance (UIR) and the apex of the root (UIA) were selected to be measured to reflect the position change of the upper incisor. The changes in the position of 
the lower central incisor and point B were measured by superimposing the T0 and T1 lateral cephalograms on the mandibular plane at the Gnathion (Fig. 3b). The antero-posterior and vertical changes in the position of the lower incisor and point $B$ were determined using the same horizontal and vertical reference lines described above. LIE, LIR and LIA, the counterparts of UIE, UIR and UIA were used to reflect the position change of the lower incisor. Pre-treatment lateral cephalometric radiographs were traced with black lines, while post-treatment cephalograms were traced with gray lines.

\section{Statistical analysis}

All measurements were conducted by two trained examiners. The intraclass correlation (ICC) was 0.96 . The average measurements were used for analysis. Since the data showed a normal distribution, $t$ tests were used. The paired t-test was used to evaluate the bony changes resulted from incisor retraction. The one-sample t-test was used to evaluate the changes in the position of the incisor and points $A$ and $B$. Pearson's correlation analysis was used to analyze the correlations between the amount of incisor movement and the position changes of points $A$ and $B$ in the horizontal direction. The statistical analyses were performed with SPSS 27.0 (IBM, Armonk, NY), with a significance level of 0.05 .

\section{Results}

The changes in $\mathrm{ABW}$ and $\mathrm{ABH}$ between $\mathrm{T} 0$ and $\mathrm{T} 1$ are shown in Table 2. In the maxilla, the labial, palatal and total alveolar bone width all decreased significantly after incisor retraction $(P<0.01, P<0.001$, and $P<0.001$, respectively). Furthermore, the palatal side exhibited significant greater bone width reduction than the labial side. In the mandible, the same decrease trend was found in both lingual and total alveolar bone width measurements $(P<0.001)$, whereas the labial bone width exhibited slight increase, though statistically insignificant $(P>0.05)$. The labial side of $A B H$ showed a significant increase in the maxilla and a significant decrease in the mandible; the lingual side of $A B H$ showed a significant decrease in mandible and maxilla.

The average changes of the points measured in this study are shown in Table 3. In sagittal direction, significant differences were observed at points UIE, UIR, UIA, A, LIE, LIR, LIA, and B after treatment. In the maxilla, the mean distance of the lingual movements of point UIE and UIR were $6.18 \pm 1.88 \mathrm{~mm}$ and $1.77 \pm 3.63 \mathrm{~mm}$, whereas the mean distance of the labial movement of point UIA was $1.15 \pm 2.00 \mathrm{~mm}$. In the mandible, points LIE, LIR and LIA all moved backwards by an average distance of $4.63 \pm 1.31 \mathrm{~mm}$, $2.86 \pm 1.24 \mathrm{~mm}$ and $1.35 \pm 1.67 \mathrm{~mm}$, respectively. In vertical direction, there were statistical differences for the displacements of all points. Point UIE moved downward, whereas points UIR and UIA moved in the opposite direction. Besides, the lower incisor showed upward movement as a whole. As shown in Table 4, a significant positive correlation was present between point $A$ and the apical point UIA. The correlation coefficient between point A and points UIE and UIR, however, was also significant on the border. The correlation coefficients between point $B$ and points LIE, LIR and LIA were also significant. Furthermore, the relationship between the displacement of the teeth and the displacement of points $A$ and $B$ was linear (Fig.4). 


\section{Discussion}

Cephalometric analysis based on lateral cephalograms has been a mature and widely used tool for the studies of craniofacial anatomical structures[18]. Cephalogram is one of the routine films requested for the orthodontic patients. Despite of the inherent defect of the 2D images, valuable information for the orthodontic treatment planning could be obtained at a low radiation dose. CBCT can be a more accurate way to measure the morphology of the alveolar bone [19]. However, the studies based on CBCT usually were conducted using a small sample size. Because no consensus has been achieved that CBCT could be taken as a routine x-ray examination before the orthodontic treatment due to the radiation issue. Therefore, in this retrospective study, a large sample consisted of pre- and post- treatment lateral cephalograms from the existed data base was used to evaluate the change in alveolar bone morphology (width and height) and investigate whether the position of points $A$ and $B$ would be affected by bone remodeling related to incisor retraction. The large sample size and comprehensive measurements lead to a greater chance for this study to reflect the most possible changes occurred incisor retraction in the orthodontic treatment.

The anterior alveolar bone defines the boundary for the retraction of the anterior teeth in orthodontic treatment. Though theoretically bone remodeling occurs during tooth movement, it remains controversial whether the changes in the anterior alveolar bone always follow the direction and quantity of tooth movement. De Angelis [3] described the bending capacity of alveolar bone, which suggested that the alveolar bone retained its structural characteristics and size as it moves with coordinated apposition and resorption. However, this bending capacity wasn't verified by other studies. The apposition and resorption of bone are in a dynamic situation during tooth movement. Melsen [20] indicated that most resorption activity occurs at sites that undergo compression, and reduced activity occurs in the tension zone. Bimstein et al. [21]suggested that the amount (mainly the height) of buccal alveolar bone might increase as a result of orthodontic treatment that involves lingual positioning of procumbent mandibular permanent central incisors without intrusion. In contrast, Sarikaya et al. [22]reported bone width in the mandible and in the lingual side of the maxilla was significantly decreased after orthodontic treatment, whereas maxillary bone thickness labial to the incisors remained unchanged. Similar results were found by Vardimon et al.[23], Ahn et al.[24], and Thongudomporn et al.[25]. One study found that upper incisor inclination and intrusion changes may increase the degree of alveolar bone loss[26]. In the present study, we found that the labial alveolar bone width showed a significant decrease in the maxilla and an insignificant increase in the mandible; the lingual side of the alveolar bone showed a significant decrease in both maxilla and mandible. Our results are consistent with the studies which showed the alveolar bone width decrease after retraction of the anterior teeth and suggested that the bone apposition process was slower than the resorption process. Significant increase of ABH was found on the labial side of the maxilla. A possible reason for this change might be the extrusion of the upper incisor during the retraction. Decrease of $\mathrm{ABH}$ was found on the palatal side of maxilla and both sides of mandible, especially the lingual side. Similar result was found by Lund et al.[16], who reported alveolar bone height decrease of the front teeth in premolar extraction cases and the most significant decrease found on the palatal/lingual side. This may due to the narrower width of the alveolar bone in the mandible, which 
would be more sensitive to the stress concentration around the cervical area from the controlled tipping movement of the lower incisor. Both the alveolar bone width and height decreased the most on the lingual side of the lower incisor suggested that more attention should be given to this area to prevent excessive bone resorption in the treatment.

The upper incisor and lower incisor were found to move in different types in this study. UIE and UIR of the maxillary incisor moved lingually by $6.18 \mathrm{~mm}$ and $1.77 \mathrm{~mm}$, respectively, whereas UIA moved labially by $1.15 \mathrm{~mm}$. This result indicated that the incisor movement during retraction in the maxilla was mainly tipping, which meant that the edge and apex of the incisor moved in the opposite direction and the center of rotation located between the center of resistance and the apex (Fig.5a). The upper incisor became more upright during the retraction. In the mandible, LIE, LIR and LIA were found to move lingually by $4.63 \mathrm{~mm} \bowtie 2.86 \mathrm{~m}$ and $1.35 \mathrm{~mm}$, which indicated the controlled tipping of lower incisors (Fig.5b). This finding is consistent with the results of Sarikaya et al.[22] and Vardimon et al[23]. who observed that in patients undergoing retraction with torque, the result was combined movement with some tipping rather than pure translation.

Root resorption is a common side-effect of orthodontic treatment, especially with extensive tooth movement. In this study, the distance between UIE and UIA in maxilla and between LIE and LIA in mandible were measured as the length for upper and lower incisor respectively. The results showed that the length of the incisor decreased by $1.02 \mathrm{~mm}$ and $1.05 \mathrm{~mm}$ in maxilla and mandible respectively, which was close to the results of the meta-analysis conducted by Samandara et al. In their study, the average amount for root resorption in anterior teeth was found to be $0.9 \mathrm{~mm}$ [27]. Kaley and Phillips [28] indicated that the contact between the root and the cortical bone is an important cause for root resorption. Horiuchi et al.[29] reported that apex approximation to the palatal cortical plate due to incisor retraction was one of the critical factors for root resorption. In addition, insufficiency of the maxillary width during tooth movement could be a risk associated with root resorption[29]. One study observed the relationship between contact the incisive canal of upper central incisors and root resorption[30]. The results showed that contact between upper incisors and the cortical plate of the incisive canal cause significantly more apical root resorption. The result of this study also showed the decrease of the alveolar bone width after incisor retraction. Therefore, the alveolar width should be carefully evaluated before the treatment to prevent excessive incisor retraction which may lead to significant root resorption.

A few previous studies focused on the effect of incisal inclination changes on points $A$ and $B$ and did not consider changes caused by the sagittal and vertical movement of the incisor[13-15, 31, 32]. Al-Nimri et al. [32] stated that, in Class II division 2 malocclusion, the movement of point A, affected by local bone remodeling, occurred in a backward direction. An earlier study by Al-Abdwani [31] stated that each $10^{\circ}$ proclination of the upper incisors resulted in a significant average change in point $A$ of $0.4 \mathrm{~mm}$ in the horizontal plane. Moreover, each $10^{\circ}$ proclination of the lower incisors resulted in a borderline significant average change in point $B$ of $0.3 \mathrm{~mm}$ in the horizontal plane. Cangialosi and Meistrell [12] studied the effect of lingual root torque on the sagittal position of point $A$, and showed that the posterior movement of the apex of the maxillary incisors resulted in a 1.7-mm posterior movement of point A. Hassan et al. 
[14] reported that there was no evidence of significant horizontal and vertical displacement of point B due to lower incisor inclination changes. In the present study, we found that point A moved backward of $0.54 \mathrm{~mm}(P<0.001)$ and downward of $0.27 \mathrm{~mm}(P \otimes 0.001)$ with the retraction of upper incisor. A positive correlation was observed between the position change of point $A$ and the displacements of points UIE, UIR and UIA. In the mandible, point B showed significant movement both in sagittal and vertical direction. In addition, a positive correlation was found between the sagittal position of point $B$ and the horizontal position changes of points LIE, LIR and LIA ( $r=0.321,0.441$ and 0.422 , respectively). The vertical displacement of point $B$ and the displacements of points of lower incisors also showed a positive correlation ( $r=0.508,0.630$ and 0.636 , respectively). The result of Pearson correlation analysis indicated that the backward movement of points $A$ and $B$ increase with the extent of incisor retraction.

Although a large sample size was used, the limitations of this study should be considered. First $\$ the age range for this sample was 11-35 years, some patients were still in growth at the time of treatment. A narrower age range should be ideal, but would also reduce the sample size considerably. Therefore, we added a statistical analysis to clarify the effect of age on the result of this study. It showed that the general differences in $\mathrm{ABW}$ and $\mathrm{ABH}$ between the post pubertal group and the pubertal group were not evident in our sample, except the bone height reduction, which was significant greater in the post pubertal group (Table $5 \&$ 6). Second, patients treated by different doctors with different treatment protocols may have different results. If all the samples were treated by one doctor, the consistency of the results would be good but less representative. Including more samples treated by different doctors will lead to a greater chance to find the general trend of the studied question. To reduce the effect of different treatment protocols on the result, the samples included in this study were all treated by fixed-appliance with extraction of 2 premolars in upper and/or lower arches and had more than $3 \mathrm{~mm}$ incisor retraction. Third, the center of resistance used in this study (UIR, LIR) was defined as a point located on the long axis of the tooth at a distance of $1 / 3$ of the root length when measured from the alveolar crest [15]. It's a well-defined point but would be affected by both the changes of the root length and the alveolar crest. To ensure the consistency of the measurement level, the pre-Tx reference line was transferred to the post-treatment cephalogram. Therefore, the UIR and LIR used in T1 ABW measurement were not the strictly defined one. We didn't find a better way in which the true center of resistance could be used at the same time when the consistency of the pre- and post-treatment measurement level could be maintained. Finally, lacking of 3D images, we couldn't know exactly to what extent incisors retraction will lead to iatrogenic sequelae such as dehiscence and fenestration. In our future researches, more details will be explored based on the results from this large sample size study serving as clues.

\section{Conclusions}

Both the alveolar bone width and height decreased following anterior teeth retraction, which suggests that alveolar bone remodeling doesn't always follows the direction and extent of orthodontic tooth movement. In most cases, the incisor retraction in orthodontic treatment was a combined movement with some tipping rather than pure translation. In addition, the position of anatomic landmarks point $A$ and $B$ could be affected by alveolar bone remodeling during orthodontic treatment. The capability of the 
anterior alveolar bone remodeling should be carefully analyzed in orthodontic treatment planning to avoid extensive incisor retraction and negative iatrogenic effects.

\section{Abbreviations}

T0: Pre-treatment; T1: Post-treatment; ABW: The alveolar bone width (ABW); ABH: The alveolar bone height; $A C$ line: $A$ line that connects the labial and palatal /lingual alveolar crest points; ABWL1, ABWP1, and ABWT1: Labial, palatal, and total alveolar width of the upper incisor, respectively; ABWL2, ABWP2, and ABWT2: Labial, lingual, and total alveolar width of the lower incisor, respectively; ABHL1 and ABHP1: labial and palatal alveolar bone height of the upper incisor, respectively; ABHL2 and ABHP2: labial and palatal alveolar bone height of the lower incisor, respectively. The cephalometric landmarks and reference planes are explained in Table 1.

\section{Declarations}

\section{Ethics approval and consent to participate}

This retrospective cephalometric study was approved by the local ethics committee (Peking University Hospital of Stomatology, NO. PKUSSIRB-201626016). Patients' consent was not obtained following the recommendations of the local review board (use of anonymized, retrospective data).

\section{Consent for publication}

Not applicable.

\section{Availability of data and material}

The datasets generated and/or analysed during the current study are not publicly available, in order to protect participant anonymity. However, these data are available from the corresponding author on reasonable request (kqbinghan@bjmu.edu.cn).

\section{Competing interests}

The authors declare that they have no competing interests.

\section{Funding}

This work was supported by grants from the National Natural Science Foundation of China (No. 51672009; No.51972005), Beijing Natural Science Foundation (No. 7172241) and Peking University Medicine Seed Fund for Interdisciplinary Research (grant number BMU 2018MI013). The funding contributed to the purchase of study materials and instrumental testing.

\section{Authors' contributions}


QS and SC contributed to data collection, analysis and development and editing of the manuscript. WL, $\mathrm{YZ}$ and LP contributed to supervision of data gathering and interpretation of results. BH contributed to conception and study design, data collection, and editing of the manuscript. All authors have read and approved the manuscript.

\section{Acknowledgements}

Not applicable.

\section{Author Details}

Department of Orthodontics, Peking University School and Hospital of Stomatology \& National Engineering Laboratory for Digital and Material Technology of Stomatology \& Beijing Key Laboratory of Digital Stomatology, 22 Zhongguancun South Avenue, Haidian District, Beijing 100081, PR China

\section{References}

1. Diels RM, Kalra V, DeLoach N, Jr., Powers M, Nelson SS. Changes in soft tissue profile of AfricanAmericans following extraction treatment. Angle Orthod. 1995; 65:285-92.

2. Baek SH, Kim BH. Determinants of successful treatment of bimaxillary protrusion: orthodontic treatment versus anterior segmental osteotomy. J Craniofac Surg. 2005; 16:234-46.

3. DeAngelis V. Observations on the response of alveolar bone to orthodontic force. Am J Orthod. 1970; 58:284-94.

4. Edwards JG. A study of the anterior portion of the palate as it relates to orthodontic therapy. Am J Orthod. 1976; 69:249-73.

5. Wehrbein H, Bauer W, Diedrich P. Mandibular incisors, alveolar bone, and symphysis after orthodontic treatment. A retrospective study. Am J Orthod Dentofacial Orthop. 1996; 110:239-46.

6. Wehrbein H, Fuhrmann RA, Diedrich PR. Periodontal conditions after facial root tipping and palatal root torque of incisors. Am J Orthod Dentofacial Orthop. 1994; 106:455-62.

7. Wainwright WM. Faciolingual tooth movement: its influence on the root and cortical plate. Am J Orthod. 1973; 64:278-302.

8. Joss-Vassalli I, Grebenstein C, Topouzelis N, Sculean A, Katsaros C. Orthodontic therapy and gingival recession: a systematic review. Orthod Craniofac Res. 2010; 13:127-41.

9. Yared KF, Zenobio EG, Pacheco W. Periodontal status of mandibular central incisors after orthodontic proclination in adults. Am J Orthod Dentofacial Orthop. 2006; 130:6.e1-8.

10. Kim SH, Lee JB, Kim MJ, Pang EK. Combining virtual model and cone beam computed tomography to assess periodontal changes after anterior tooth movement. BMC Oral Health. 2018; 18:180.

11. Mills JR. The effects of orthodontic treatment on the skeletal pattern. Br J Orthod. 1978; 5:133-43.

12. Cangialosi TJ, Meistrell ME, Jr. A cephalometric evaluation of hard- and soft-tissue changes during the third stage of Begg treatment. Am J Orthod. 1982; 81:124-9. 
13. Erverdi N. A cephalometric study of changes in point A under the influence of upper incisor inclinations. J Nihon Univ Sch Dent. 1991; 33:160-5.

14. Hassan S, Shaikh A, Fida M. EFFECT OF INCISOR INCLINATION CHANGES ON CEPHALOMETRIC POINTS A AND B. J Ayub Med Coll Abbottabad. 2015; 27:268-73.

15. Bicakci AA, Cankaya OS, Mertoglu S, Yilmaz N, Altan BK. Does proclination of maxillary incisors really affect the sagittal position of point A? Angle Orthod. 2013; 83:943-7.

16. Lund H, Gröndahl K, Gröndahl HG. Cone beam computed tomography evaluations of marginal alveolar bone before and after orthodontic treatment combined with premolar extractions. Eur $\mathrm{J}$ Oral Sci. 2012; 120:201-11.

17. Burstone CJ, Every TW, Pryputniewicz RJ. Holographic measurement of incisor extrusion. Am J Orthod. 1982; 82:1-9.

18. Jung PK, Lee GC, Moon CH. Comparison of cone-beam computed tomography cephalometric measurements using a midsagittal projection and conventional two-dimensional cephalometric measurements. Korean J Orthod. 2015; 45:282-8.

19. Gribel BF, Gribel MN, Frazao DC, McNamara JA, Jr., Manzi FR. Accuracy and reliability of craniometric measurements on lateral cephalometry and 3D measurements on CBCT scans. Angle Orthod. 2011; 81:26-35.

20. Melsen B. Biological reaction of alveolar bone to orthodontic tooth movement. Angle Orthod. 1999; 69:151-8.

21. Bimstein E, Crevoisier RA, King DL. Changes in the morphology of the buccal alveolar bone of protruded mandibular permanent incisors secondary to orthodontic alignment. Am J Orthod Dentofacial Orthop. 1990; 97:427-30.

22. Sarikaya S, Haydar B, Ciger S, Ariyurek M. Changes in alveolar bone thickness due to retraction of anterior teeth. Am J Orthod Dentofacial Orthop. 2002; 122:15-26.

23. Vardimon AD, Oren E, Ben-Bassat $Y$. Cortical bone remodeling/tooth movement ratio during maxillary incisor retraction with tip versus torque movements. Am J Orthod Dentofacial Orthop. 1998; 114:52029.

24. Ahn HW, Moon SC, Baek SH. Morphometric evaluation of changes in the alveolar bone and roots of the maxillary anterior teeth before and after en masse retraction using cone-beam computed tomography. Angle Orthod. 2013; 83:212-21.

25. Thongudomporn U, Charoemratrote $C$, Jearapongpakorn S. Changes of anterior maxillary alveolar bone thickness following incisor proclination and extrusion. Angle Orthod. 2015; 85:549-54.

26. Atik E, Gorucu-Coskuner H, Akarsu-Guven B, Taner T. Evaluation of changes in the maxillary alveolar bone after incisor intrusion. Korean J Orthod. 2018; 48:367-76.

27. Samandara A, Papageorgiou SN, Ioannidou-Marathiotou I, Kavvadia-Tsatala S, Papadopoulos MA. Evaluation of orthodontically induced external root resorption following orthodontic treatment using cone beam computed tomography (CBCT): a systematic review and meta-analysis. Eur $\mathrm{J}$ Orthod. 2019; 41:67-79. 
28. Kaley J, Phillips C. Factors related to root resorption in edgewise practice. Angle Orthod. 1991; 61:125-32.

29. Horiuchi A, Hotokezaka H, Kobayashi K. Correlation between cortical plate proximity and apical root resorption. Am J Orthod Dentofacial Orthop. 1998; 114:311-18.

30. Pan Y, Chen S. Contact of the incisive canal and upper central incisors causing root resorption after retraction with orthodontic mini-implants: A CBCT study. Angle Orthod. 2019; 89:200-5.

31. Al-Abdwani R, Moles DR, Noar JH. Change of incisor inclination effects on points A and B. Angle Orthod. 2009; 79:462-7.

32. Al-Nimri KS, Hazza'a AM, Al-Omari RM. Maxillary incisor proclination effect on the position of point A in Class II division 2 malocclusion. Angle Orthod. 2009; 79:880-4.

\section{Tables}

Table 1. Cephalometric landmarks and reference plane measurements 


\begin{tabular}{|c|c|c|}
\hline Landmark/Plane & Abbreviatior & Definition \\
\hline Sella & S & The center of the pituitary fossa of the sphenoid bone. \\
\hline Nasion & $\mathrm{N}$ & $\begin{array}{l}\text { The junction of the frontonasal suture at the most } \\
\text { posterior point on the curve at the bridge of the nose. }\end{array}$ \\
\hline Porion & Po & The most superior point of the external auditory meatus. \\
\hline Orbitale & Or & $\begin{array}{l}\text { The lowest point on the average of the right and left } \\
\text { borders of the bony orbit. }\end{array}$ \\
\hline $\begin{array}{l}\text { Posterior nasal } \\
\text { spine }\end{array}$ & PNS & The tip of the posterior nasal spine. \\
\hline $\begin{array}{l}\text { Anterior nasal } \\
\text { spine }\end{array}$ & ANS & The tip of the anterior nasal spine. \\
\hline Point A & A & $\begin{array}{l}\text { The most posterior point on the curve of the maxilla } \\
\text { between the anterior nasal spine and superdentale. }\end{array}$ \\
\hline $\begin{array}{l}\text { Upper incisor } \\
\text { edge }\end{array}$ & $\mathrm{UIE}$ & $\begin{array}{l}\text { The incisal edge point of the most prominent upper central } \\
\text { incisor. }\end{array}$ \\
\hline $\begin{array}{l}\text { Upper incisor } \\
\text { apex }\end{array}$ & UIA & $\begin{array}{l}\text { The incisal apex of the most prominent upper central } \\
\text { incisor. }\end{array}$ \\
\hline $\begin{array}{l}\text { Upper incisor } \\
\text { resistance }\end{array}$ & UIR & $\begin{array}{l}\text { The intersection point of the root axis and the upper } \\
\text { border of the cervical third of the root. }\end{array}$ \\
\hline Point B & B & $\begin{array}{l}\text { The most posterior point to a line from infradentale to } \\
\text { pogonion on the anterior surface of the symphyseal outline } \\
\text { of the mandible. }\end{array}$ \\
\hline $\begin{array}{l}\text { Lower incisor } \\
\text { edge }\end{array}$ & LIE & $\begin{array}{l}\text { The incisal edge point of the most prominent lower central } \\
\text { incisor. }\end{array}$ \\
\hline $\begin{array}{l}\text { Lower incisor } \\
\text { apex }\end{array}$ & LIA & $\begin{array}{l}\text { The incisal apex of the most prominent lower central } \\
\text { incisor. }\end{array}$ \\
\hline $\begin{array}{l}\text { Lower incisor } \\
\text { resistence }\end{array}$ & LIR & $\begin{array}{l}\text { The intersection point of the root axis and the lower } \\
\text { border of the cervical third of the root. }\end{array}$ \\
\hline Gonion & Go & $\begin{array}{l}\text { The bisector of the angle between tangent through the } \\
\text { posterior margin of the ascending ramus and tangent to } \\
\text { Page } 13 / 21\end{array}$ \\
\hline
\end{tabular}


the mandibular base at menton.

\begin{tabular}{|c|c|c|}
\hline Gnathion & Gn & $\begin{array}{l}\text { The most anterior-inferior point on the contour of the bony } \\
\text { chin symphysis. }\end{array}$ \\
\hline $\begin{array}{l}\text { Sella-Nasion } \\
\text { plane }\end{array}$ & SN & The plane through sella and nasion. \\
\hline Frankfort plane & FH & The plane through porion and orbitale. \\
\hline Palatal plane & $\mathrm{PP}$ & The plane through ANS and PNS. \\
\hline $\begin{array}{l}\text { Mandibular } \\
\text { plane }\end{array}$ & MP & The plane through gonion and menton. \\
\hline $\begin{array}{l}\text { Horizontal } \\
\text { reference plane }\end{array}$ & HRP & The plane parallel to FH plane passing through sella. \\
\hline $\begin{array}{l}\text { Vertical } \\
\text { reference plane }\end{array}$ & VRP & The plane was drawn as a perpendicular to HRP at sella. \\
\hline
\end{tabular}

Table 2. Changes of the anterior alveolar bone width and height before (T0) and after (T1) orthodontic treatment ${ }^{\mathrm{ab}}$ 


\begin{tabular}{|c|c|c|c|c|c|}
\hline solar bone & T0 & $\mathrm{T} 1$ & T1-T0 & & $\mathrm{N}$ \\
\hline $\mathrm{ln} \pm \mathrm{SD}(\mathrm{mm})$ & Mean $\pm S D(m m)$ & $\operatorname{Mean} \pm \mathrm{SD}(\mathrm{mm})$ & $\mathrm{P}$ value & & \\
\hline VL1 & $1.82 \pm 0.38$ & $1.77 \pm 0.39$ & $-0.05 \pm 0.45$ & $.009 * * *$ & 477 \\
\hline VP1 & $3.16 \pm 0.80$ & $2.94 \pm 0.80$ & $-0.22 \pm 0.84$ & $.000 * * *$ & 477 \\
\hline VT1 & $11.63 \pm 1.31$ & $10.68 \pm 1.37$ & $-0.95 \pm 1.11$ & $.000 * * *$ & 477 \\
\hline IL1 & $18.32 \pm 2.35$ & $19.53 \pm 2.64$ & $1.21 \pm 1.41$ & $.000 * * *$ & 477 \\
\hline IP1 & $22.09 \pm 2.22$ & $21.87 \pm 2.42$ & $-0.22 \pm 1.35$ & $.000 * * *$ & 477 \\
\hline VL2 & $1.78 \pm 0.45$ & $1.79 \pm 0.43$ & $.009 \pm 0.47$ & .781 & 266 \\
\hline VP2 & $1.84 \pm 0.43$ & $1.49 \pm 0.33$ & $-.35 \pm 0.41$ & $.000 * * *$ & 266 \\
\hline VT2 & $8.57 \pm 0.90$ & $7.85 \pm 0.75$ & $-.72 \pm 0.85$ & $.000 * * *$ & 266 \\
\hline IL2 & $30.02 \pm 3.14$ & $29.53 \pm 3.44$ & $-0.49 \pm 1.86$ & $.000 * * *$ & 266 \\
\hline IP2 & $30.65 \pm 3.14$ & $29.37 \pm 3.30$ & $-1.28 \pm 1.64$ & $.000 * * *$ & 266 \\
\hline
\end{tabular}

aABWL1, ABWP1, and ABWT1: labial, palatal, and total alveolar width of the upper incisor, respectively; ABWL2, ABWP2, and ABWT2: labial, lingual, and total alveolar width of the lower incisor, respectively. ABHL1 and ABHP1: labial and palatal alveolar bone height of the upper incisor, respectively; ABHL2 and ABHP2: labial and palatal alveolar bone height of the lower incisor, respectively.

b* $\mathrm{P}<0.05$; ** $\mathrm{P}<0.01 ; * * * \mathrm{P}<0.001$

Table 3. Treatment changes of points in the horizontal direction ${ }^{\mathrm{ab}}$ 


\begin{tabular}{llll}
\hline Variable & Mean \pm SD $(\mathrm{mm})$ & $\mathrm{p}$-value & $\mathrm{N}$ \\
\hline UIE-h & $-6.18 \pm 1.88$ & $.000 * * *$ & 477 \\
UIR-h & $-1.77 \pm 3.63$ & $.000 * * *$ & 477 \\
UIA-h & $1.15 \pm 2.00$ & $.000 * * *$ & 477 \\
A-h & $-0.54 \pm 1.19$ & $.000^{* * *}$ & 477 \\
UIE-v & $-1.29 \pm 1.63$ & $.000^{* * *}$ & 477 \\
UIR-v & $0.30 \pm 1.53$ & $.002 * * *$ & 477 \\
UIA-v & $.69 \pm 1.59$ & $.000 * * *$ & 477 \\
A-v & $-.27 \pm 1.01$ & $.000 * * *$ & 477 \\
LIE-h & $-4.63 \pm 1.31$ & $.000 * * *$ & 226 \\
LIR-h & $-2.86 \pm 1.24$ & $.000 * * *$ & 226 \\
LIA-h & $-1.35 \pm 1.67$ & $.000 * * *$ & 226 \\
B-h & $-0.60 \pm 1.00$ & $.000 * * *$ & 226 \\
LIE-v & $1.73 \pm 2.28$ & $.000 * * *$ & 226 \\
LIR-v & $0.79 \pm 1.87$ & $.000 * * *$ & 226 \\
LIA-v & $0.62 \pm 2.04$ & $.000 * * *$ & 226 \\
B-v & $1.54 \pm 1.80$ & $.000 * * *$ & 226 \\
UTL & $-1.02 \pm 1.50$ & $.000 * * *$ & 226 \\
LTL & $-1.05 \pm 1.45$ & $.000 * * *$ & 226 \\
\hline
\end{tabular}

$\mathrm{a}_{\mathrm{h}}$ : horizontal displacement of points; v: vertical displacement of points; UTL: tooth length of the upper incisor; LTL: tooth length of the lower incisor.

$\mathrm{b}_{* * *} \mathrm{P}<0.001$

Table 4. Pearson correlation Coefficients and P Values Between incisors movement and the displacements of points $\mathrm{A}$ and $\mathrm{B}^{\mathrm{ab}}$ 


\begin{tabular}{lll}
\hline Variable & coefficient & P value \\
\hline A-h \& UIE-h & 0.196 & $.000 * * *$ \\
A-h \& UIR-h & 0.278 & $.000 * * *$ \\
A-h \& UIA-h & 0.621 & $.000 * * *$ \\
A-v\&UIE-v & 0.414 & $.000 * * *$ \\
A-v \& UIR-v & 0.220 & $.000 * * *$ \\
A-v \& UIA-v & 0.441 & $.000 * * *$ \\
B-h\&LIE-h & 0.321 & $.000 * * *$ \\
B-h\& LIR-h & 0.441 & $.000 * * *$ \\
B-h \& LIA-h & 0.422 & $.000 * * *$ \\
B-v\&LIE-v & 0.508 & $.000 * * *$ \\
B-v \& LIR-v & 0.630 & $.000 * * *$ \\
B-v \& LIA-v & 0.636 & $.000 * * *$ \\
\hline
\end{tabular}

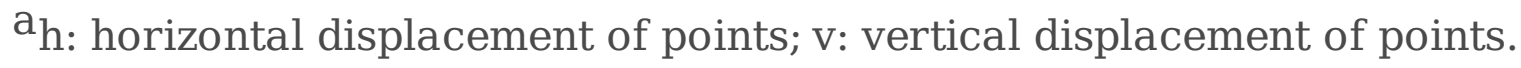

$\mathrm{b}_{* * *} \mathrm{P}<0.001$

Table 5. Changes of the anterior alveolar bone width and height of different age in the maxilla ${ }^{\mathrm{abc}}$

\begin{tabular}{lllll}
\hline Alveolar bone & $\mathrm{P} 1$ & $\mathrm{P} 2$ & $\mathrm{P} 2-\mathrm{P} 1$ & \\
& $\square \mathrm{N}=348 \square$ & $\square \mathrm{N}=129 \square$ & & \\
\cline { 2 - 5 } & Mean $\pm \mathrm{SD}(\mathrm{mm})$ & Mean $\pm \mathrm{SD}(\mathrm{mm})$ & Mean $\pm \mathrm{SD}(\mathrm{mm})$ & P value \\
\hline ABWL1 & $-0.05 \pm 0.44$ & $-0.07 \pm 0.47$ & $-0.02 \pm 0.05$ & .622 \\
ABWP1 & $-0.27 \pm 0.88$ & $-0.10 \pm 0.73$ & $0.17 \pm 0.09$ & $.049^{*}$ \\
ABWT1 & $-0.97 \pm 1.16$ & $-0.91 \pm 0.98$ & $0.07 \pm 0.11$ & .561 \\
ABHL1 & $1.31 \pm 1.45$ & $0.94 \pm 1.26$ & $-0.37 \pm 0.14$ & $.007^{* * *}$ \\
ABHP1 & $-0.04 \pm 1.39$ & $-0.71 \pm 1.12$ & $-0.67 \pm 0.12$ & $.000^{* * *}$ \\
\hline
\end{tabular}


aABWL1, ABWP1, and ABWT1: labial, palatal, and total alveolar width of the upper incisor, respectively; ABHL1 and ABHP1: labial and palatal alveolar bone height of the upper incisor, respectively.

$\mathrm{b}_{\mathrm{P} 1}$ (the pubertal group) $\square 11 \mathrm{y} \leq \mathrm{age} \llbracket 16 \mathrm{y} ; \mathrm{P} 2$ (the post pubertal group): age $\geq 16 \mathrm{y}$.

$\mathrm{C} * \mathrm{P}<0.05 ; * * \mathrm{P}<0.01 ; * * * \mathrm{P}<0.001$

Table 6. Changes of the anterior alveolar bone width and height of different age in the mandible $e^{\mathrm{abc}}$

\begin{tabular}{lllll}
\hline Alveolar bone & $\mathrm{P} 1$ & $\mathrm{P} 2$ & $\mathrm{P} 2-\mathrm{P} 1$ & \\
& $\square \mathrm{N}=159 \square$ & $\square \mathrm{N}=67 \square$ & & \\
\cline { 2 - 5 } & $\mathrm{Mean} \pm \mathrm{SD}(\mathrm{mm})$ & Mean $\pm \mathrm{SD}(\mathrm{mm})$ & Mean $\pm \mathrm{SD}(\mathrm{mm})$ & P value \\
\hline ABWL2 & $0.02 \pm 0.42$ & $-0.01 \pm 0.57$ & $-0.03 \pm 0.08$ & .727 \\
ABWP2 & $-0.36 \pm 0.40$ & $-0.31 \pm 0.43$ & $0.05 \pm 0.06$ & .368 \\
ABWT2 & $-0.76 \pm 0.74$ & $-0.63 \pm 1.08$ & $0.14 \pm 0.12$ & .343 \\
ABHL2 & $-0.04 \pm 1.83$ & $-1.54 \pm 1.48$ & $-1.50 \pm 0.25$ & $.000^{* * *}$ \\
ABHP2 & $-0.90 \pm 1.65$ & $-2.18 \pm 1.21$ & $-1.29 \pm 0.22$ & $.000^{* * *}$ \\
\hline
\end{tabular}

aABWL2, ABWP2, and ABWT2: labial, lingual, and total alveolar width of the lower incisor, respectively; ABHL2 and ABHP2: labial and palatal alveolar bone height of the lower incisor, respectively.

$\mathrm{b}_{\mathrm{P} 1}$ (the pubertal group) $\square 11 \mathrm{y} \leq \mathrm{age} \llbracket 16 \mathrm{y}$; $\mathrm{P} 2$ (the post pubertal group): age $\geq 16 \mathrm{y}$.

$\mathrm{C} * \mathrm{P}<0.05 ; * * \mathrm{P}<0.01 ; * * * \mathrm{P}<0.001$

\section{Figures}




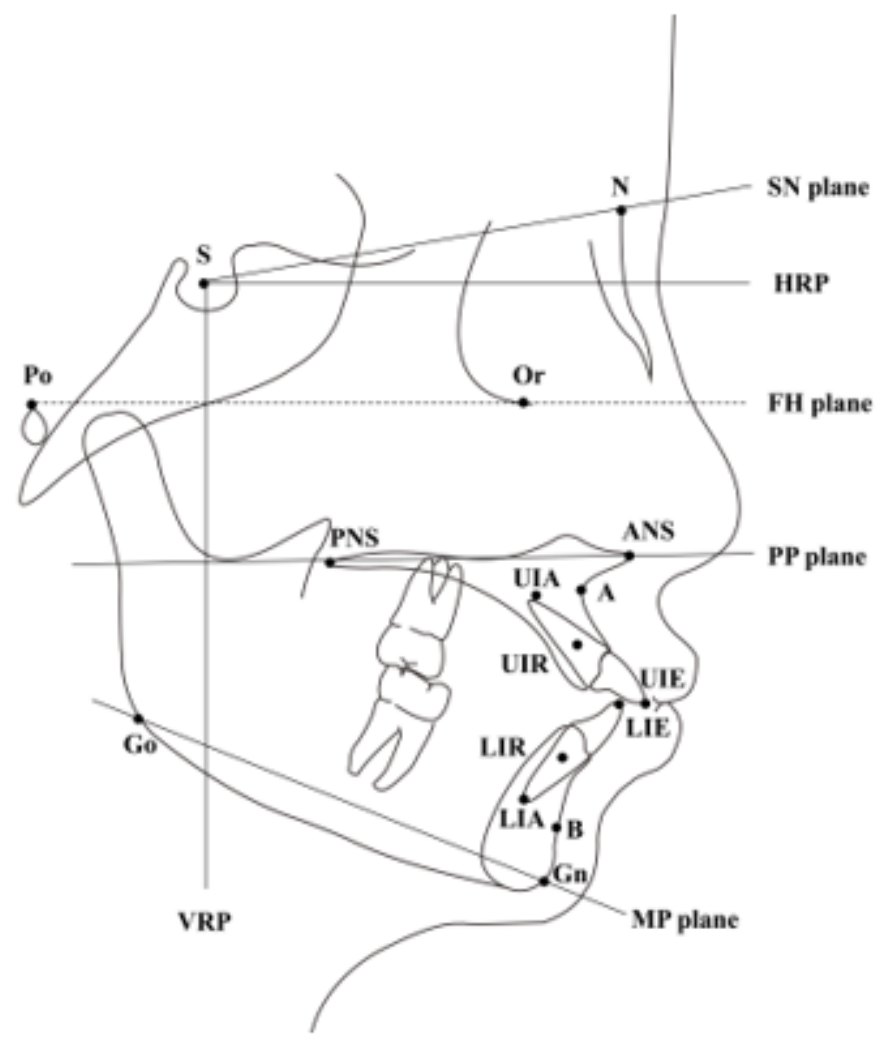

\section{Figure 1}

Illustration of cephalometric landmarks and reference planes.

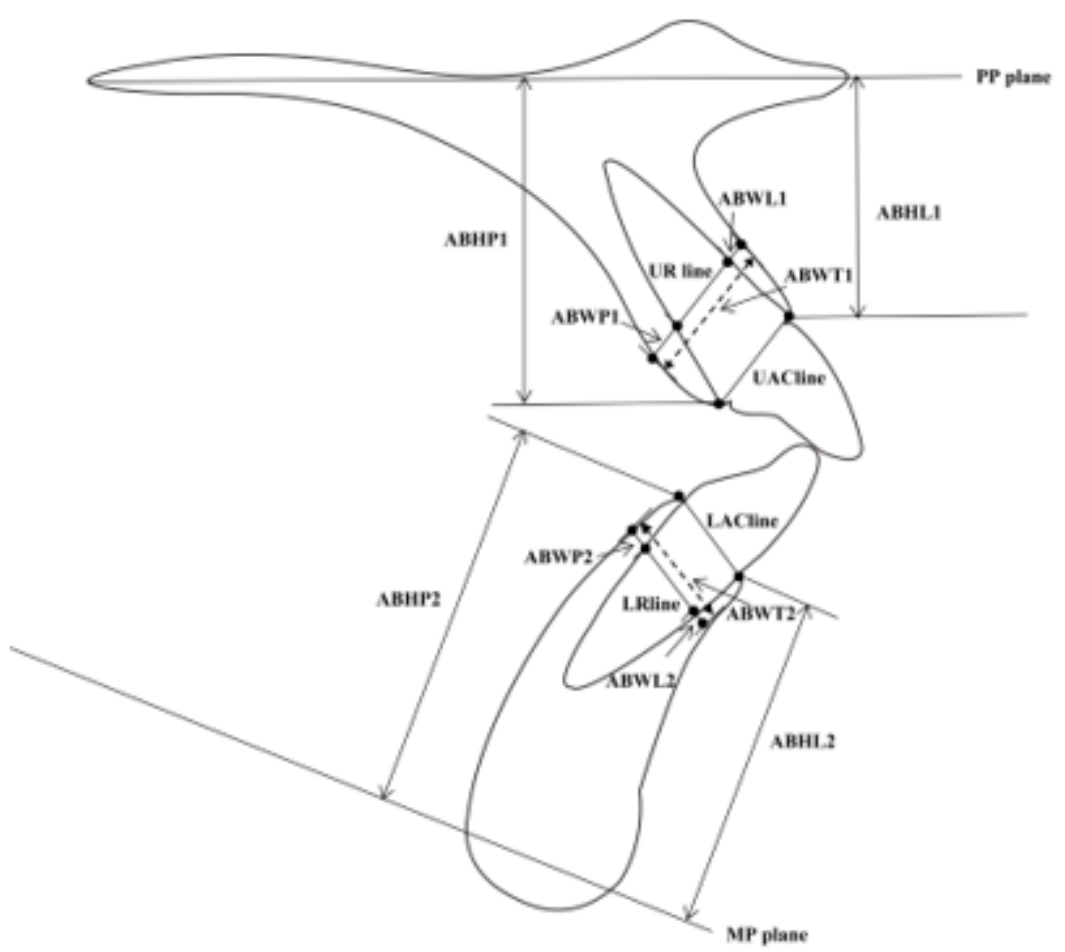

Figure 2 
Alveolar bone width and height measurements before and after treatment. UAC line: a line that connects the labial and palatal alveolar crest (AC) points of upper incisor; UR line: a line parallel with UAC line passing through the center of resistance of the upper incisor (UIR); ABWL1, ABWP1, and ABWT1: labial, palatal, and total alveolar bone width of the upper incisor, respectively; LAC line: a line that connects the $A C$ points of the lower incisor; LR line: a line parallel to $L A C$ line passing through the center of resistance of the lower incisor (LIR); ABWL2, ABWP2, and ABWT2: labial, lingual, and total alveolar bone width of the lower incisor, respectively; $A B H L 1$ and ABHP1:labial and palatal alveolar bone height of the upper incisor, respectively; $A B H L 2$ and $A B H P 2: l a b i a l$ and palatal alveolar bone height of the upper incisor, respectively.
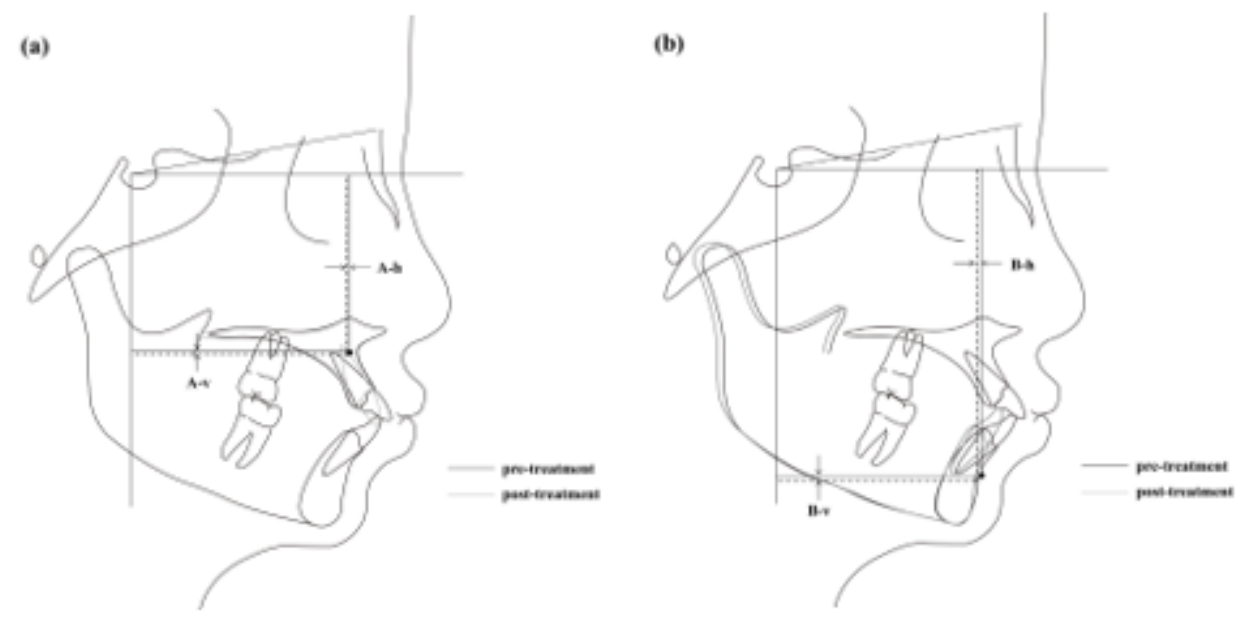

\section{Figure 3}

(a): Illustration of the superimposition of pre- and post-treatment tracings on the palatal plane at the ANS to determine the change in the position of point A. (b): Illustration of the superimposition of pre- and posttreatment tracings on the mandibular plane at the gnathion to determine the change in the position of point B. 

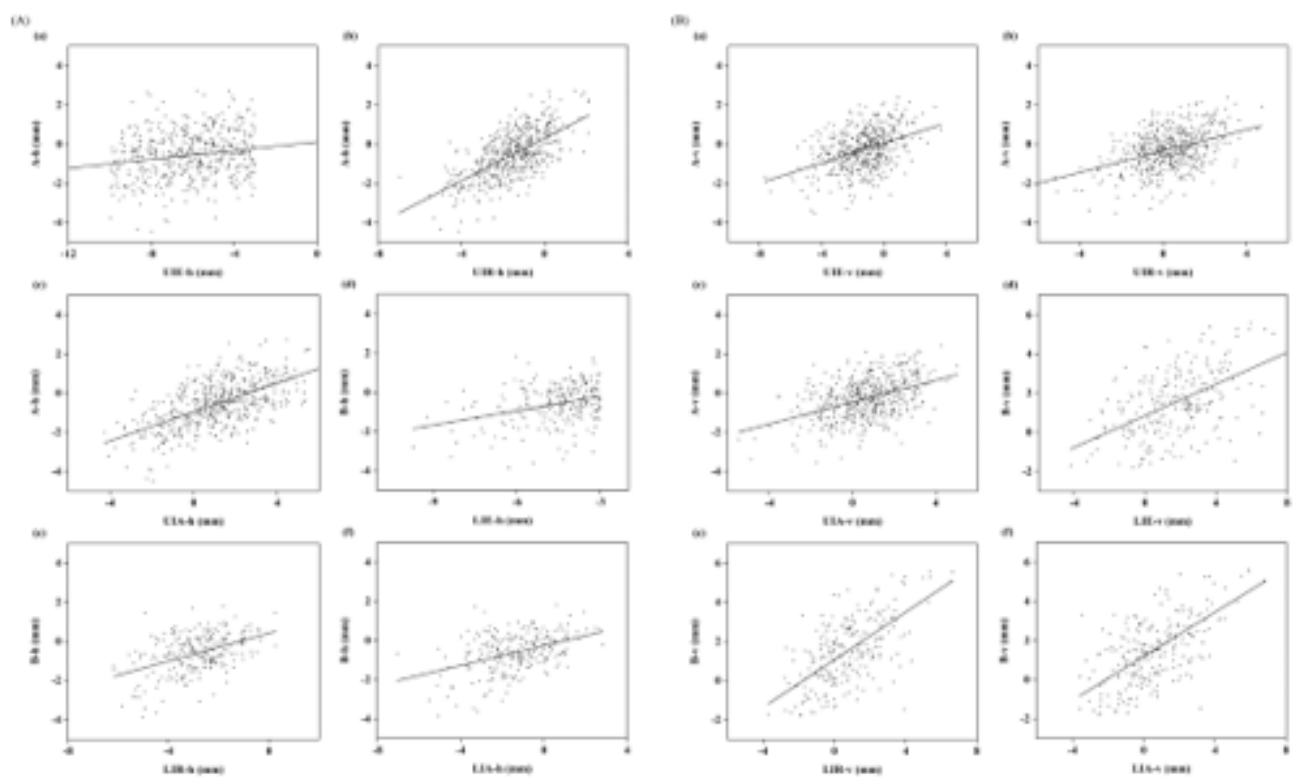

\section{Figure 4}

(A): Scatterplot of the sagittal position changes for the incisor and points A and B. (B): Scatterplot of the vertical position changes for the incisor and points $A$ and $B$.

(a)

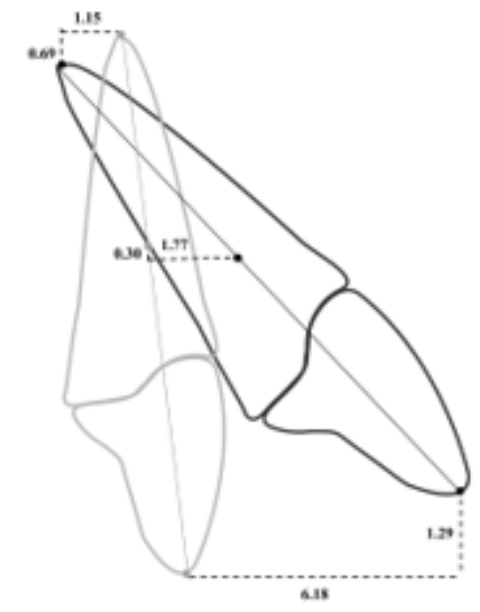

(b)

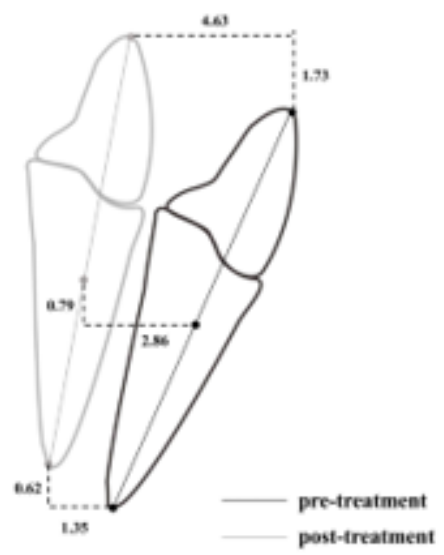

Figure 5

(a): Illustration of tooth movements of upper incisor after orthodontic treatment. (b): Illustration of tooth movements of lower incisor after orthodontic treatment.

\section{Supplementary Files}

This is a list of supplementary files associated with this preprint. Click to download.

- SupplementaryMaterial.pdf 